\title{
Female infanticide and female-directed lethal targeted aggression in a group of ring-tailed lemurs (Lemur catta)
}

\author{
Klara Kittler $^{1}$ and Silvio Dietzel ${ }^{2}$ \\ ${ }^{1}$ Behavioral Ecology \& Sociobiology Unit, German Primate Center, 37077 Göttingen, Germany \\ ${ }^{2}$ Erlebnispark Affenwald, 99706 Straußberg, Germany \\ Correspondence to: Klara Kittler (klara.kittler@gmx.de)
}

Received: 25 January 2016 - Revised: 26 July 2016 - Accepted: 8 August 2016 - Published: 16 August 2016

\begin{abstract}
We report on extremely rare events of lethal aggression in a semi-captive group of ring-tailed lemurs (Lemur catta) during the birth season 2014. This aggression was targeted against the two highest-ranking females. It led to their eviction from the group and following a final aggressive interaction four days later to their deaths caused by almost all the females and probably even two males of their former group. These events of targeted aggression erupted initially following an infanticide by the highest-ranking female directed at the offspring of a subordinate. Even for ring-tailed lemurs this is a very special case of changeover of power between two different matrilines in a group. In accordance with other studies we suggest that these events of targeted aggression were based on the growing group size and were acts of female reproductive competition during birth season. With the intensity of the events we add new aspects to the existing knowledge of aggressive interactions in ring-tailed lemurs.
\end{abstract}

\section{Introduction}

Intraspecific aggression with lethal outcome among primates is essentially limited to infanticide and usually conducted by males (Hrdy, 1977; Bartlett et al., 1993; reviewed in van Schaik, 2000). Infanticide by non-maternal females is rare and has so far only been reported for a few primate species (e.g. Pan: Goodall, 1977; Callithrix: Digby, 1995; Macaca: Muroyama and Thierry, 1996; Eulemur and Lemur: Andrews, 1998; Jolly et al., 2000). The infanticidal females usually harassed and attacked the typically subordinate mother of the infant victim, with the victim either directly attacked and killed or incidentally killed by the fighting females.

Under rare circumstances, adult primates can become victims of lethal aggressions, as well. Most of the few observed cases have happened in wild chimpanzees (Fawcett and Muhumuza, 2000; Watts, 2004), but killing of adult group members has also been reported for capuchin and spider monkeys (Gros-Louis et al., 2003; Valero et al., 2006). In all these reported cases of lethal intragroup aggression the victims were either young or peripheral males. Their attackers were in each case other male group members, acting alone or in coalition with several other males, supporting the interpretation that these fights were acts of male sexual competition. However, the rare event of a female-led coalitionary attack on another female was recently reported from Bornean orangutans (Pongo pygmaeus wurmbii; Marzec et al., 2016), which emphasizes the leverage females have over males.

Here, we report events of intragroup aggression in a semicaptive group of ring-tailed lemurs (Lemur catta), where the two dominant females were targeted and which resulted in their death. In the wild ring-tailed lemurs live in large multimale/multi-female groups ranging approximately 3-22 individuals (average group sizes vary between 11 and 14 individuals, depending on the habitat; Jolly, 1966; Sussman, 1991; Gould et al., 2003; Mittermeier et al., 2006). Both sexes exhibit clear dominance hierarchies and females are philopatric and dominant over males (Jolly, 1966; Budnitz and Dainis, 1975; Kappeler, 1990; Sauther et al., 1999). The matriline is the core of the group, and in larger groups that contain more than one matriline, one matriline is usually dominant over the others (Taylor and Sussman, 1985; Sussman, 1991; Nakamichi and Koyama, 1997; Jolly, 2003). Compared to other lemur species, ring-tailed lemurs exhibit 
high rates of agonism (Jolly, 1966, 1998; Erhart and Overdorff, 2008). Intragroup aggression occurs mainly intrasexually or is directed from females towards males but rarely reversed (Jolly, 1966; Kappeler, 1990; Hood and Jolly, 1995; Sauther et al., 1999; Charpentier and Drea, 2013). Aggressive interactions include lunging, chasing, grabbing and biting (e.g. Jolly et al., 1993; Pereira, 1993; Pereira and Kappeler, 1997; Jolly et al., 2000; Charpentier and Drea, 2013), and escalated targeted aggression may result in eviction of targeted individuals, who are often subordinate members of another matriline (Vick and Pereira, 1989; Koyama, 1991; Jolly et al., 2002; Gould et al., 2003). Indeed, most instances of targeted aggression have been observed between different matrilines during mating and birth season or after a group has exceeded a certain size and was close to a group fission (Vick and Pereira, 1989). Targeted aggression by dominant females and the eviction of subdominant females from the group are therefore interpreted as one form of female reproductive competition and have been observed in the wild, as well as in free-ranging captive populations (Vick and Pereira, 1989; Gould, 1990; Koyama, 1991; Sauther, 1991; Pereira and Kappeler, 1997; Sauther et al., 1999; Jolly et al., 2000; Gould et al., 2003; Kappeler and Fichtel, 2012).

Infanticide occurs occasionally in ring-tailed lemurs but has so far mainly been perpetrated by males (e.g. Hood, 1994; Jolly et al., 2000; Ichino, 2005). In most cases it happened during an intertroop encounter, and the infanticidal male was from a neighbouring group or a recent immigrant, hence unrelated to the infant (e.g. Ichino, 2005). In contrast, only a few attacks by females on infants have been reported. Just a few of them ended deadly, and all of them occurred within a group (Jolly et al., 2000; Charpentier and Drea, 2013). In all cases the attack was conducted by high-ranking females towards the infant of an unrelated subordinate female. Here, we report a case of female infanticide that took place during the birth season and mainly included the two highest-ranking matrilines of the group. In contrast to previous reports, however, infanticide was followed by lethal aggression towards the perpetrators.

\section{Methods}

The present observations were conducted at Affenwald, an animal park in Thuringia (Germany). The free-ranging population of ring-tailed lemurs at the Affenwald inhabits a large natural outdoor enclosure ( $3.5 \mathrm{ha}$ ) covered mainly with beech trees (Fagus sylvatica). The enclosure is surrounded by an electric fence $(2.5 \mathrm{~m})$, which ensures that the lemurs cannot leave and also prevents local predators like foxes from entering the enclosure. The lemurs forage freely on the vegetation of the enclosure, but they are also provisioned daily with fresh fruits and vegetables. The enclosure is equipped with several small huts that offer warm indoor areas, which the lemurs mainly visit at night and during winter. At the
Table 1. Composition of the two ring-tailed lemur groups at Affenwald during the events. Group A is the focal group described in this study.

\begin{tabular}{lccccc}
\hline Species & & Males & Females & Subadults & Infants \\
\hline Lemur & group A & 4 & 5 & 5 & 4 \\
catta & group B & 6 & 4 & 4 & 5 \\
\hline
\end{tabular}

time of the events reported below, Affenwald was inhabited by 37 ring-tailed lemurs, 14 black-and-white ruffed lemurs (Varecia variegata) and 3 Bennett's wallabies (Macropus rufogriseus). The ring-tailed lemurs lived in two groups (A and $\mathrm{B}$, see Table 1 for the composition of both groups), which defend their territory against each other and exhibit natural aggressive interactions between and within the groups on a daily basis. These interactions sometimes lead to plucked fur or even injuries resulting from bites, but usually the level of injuries is not severe and no adult individual has ever been critically injured. Furthermore, a female eviction from a group has, so far, happened only once, when an old female was evicted from her group (A) and lived afterwards at the border of their territory together with an old male. The focal group (A) consisted of nine adult individuals in late March/early April 2014, when eight of the nine adult females of both groups of ring-tailed lemurs gave birth (see Table 1).

The dominance hierarchy of the females was determined for previous experiments using a food monopolization test with only one high-quality food source available at a time. It revealed Casey to be the highest-ranking female in the group, followed in rank by her twin sister, Ceres (matriline 1; see Fig. 1).

Since no researcher was conducting focal observations during the time of the events, all reports are based on very detailed daily observations by Silvio Dietzel and the animal care takers of Affenwald. Therefore, actual quantitative data on, for example, aggressive interactions or attacks, were not collected.

\section{Results}

Here we summarize the events of the infanticide and the following lethal targeted aggression in their chronological order.

14 March: Ifaty gave birth to one infant.

18 March: Casey gave birth to one infant, but she did not take good care of it (she handled it roughly and sometimes just left it behind).

20 March: Casey's infant was missing and had probably died, but the carcass was never found.

20-27 March: Casey and Ceres increasingly harassed (lunges and grabs) Ifaty and her infant aggressively. 


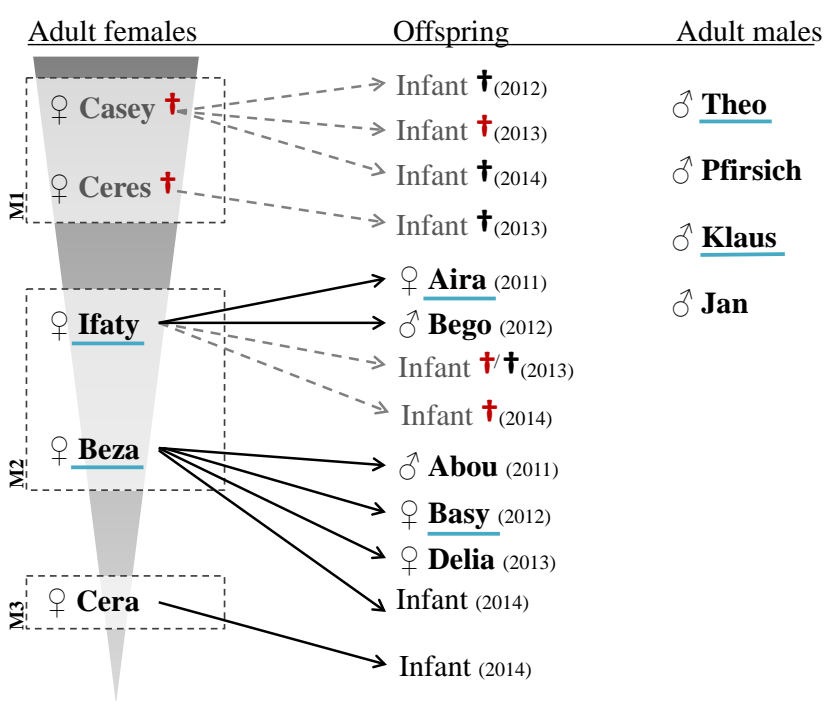

Figure 1. Composition of group A in spring 2014 and the relationships between the individuals; M: matriline; grey triangle: female rank order, from highest to lowest; $\boldsymbol{\dagger}$ was killed by a conspecific; † died for unknown reasons; underlined: showed obvious signs of a fight after the events (injuries or plucked fur); paternities are unknown.

However, since the time Casey's infant went missing, she herself was often avoided or aggressively grabbed by other members of the group, except for Ceres, who always stayed close to her, huddled and groomed with her.

27 March: Ifaty's infant got caught up in the middle of an agonistic interaction between Ifaty and Casey and was fatally bitten by Casey. It received several bites to the abdomen and the upper thighs and died.

27-31 March: The observed infanticide immediately led to increased aggression (chases, grabs and aggressive attacks including biting) of the whole group towards Casey and Ceres. By the end of that day (27 March) they were both evicted from the group and chased away on every encounter. For several days they tried to contact and reconcile with different group members (attempted approaches and grooming), but they were continuously repelled and chased aggressively. Additionally, both females were not allowed to sleep with the group in the houses during the night, but huddled up together in a tree some distance away. Because previous conflicts had always been settled within a few days, there was no intervention by the Affenwald staff.

1 April: In the early morning Casey was found dead, with numerous severe bite marks at the throat, neck and legs. Ceres also suffered severe wounds and, despite veterinary intervention, died one day later. Both females showed severe bite marks consistent with those of ring- tailed lemurs and not consistent with the actions of a predator. Moreover, after the incident a visual examination of all other group members revealed that most females and two males of the group exhibited several injuries, bites or spots of plucked fur (see Fig. 1), indicating that they had participated in fighting. The patterns of injuries suggested that the four most engaged individuals had been the females of matriline 2, Ifaty and Beza, and their subadult daughters. The other adult female Cera (matriline 3) is not related to either of the other matrilines and did not appear to have taken part in the fighting, as no injuries were evident. However, in the following days she avoided close contact with the other two females (e.g. when resting she stayed at a distance to them, usually accompanied by one or two males).

\section{Discussion}

Less than a week after the incident of an infanticide, the two highest-ranking females of a group of ring-tailed lemurs had lost their status, were evicted and 4 days later attacked lethally by former group members. These events illustrate that female intrasexual aggression in ring-tailed lemurs can become extremely intense and lead to a rank reversal of an entire matriline. Episodes of female targeted aggression and group evictions have already been reported for members of different matrilines, in both captive and wild groups, and the majority also happened during birth season (e.g. Vick and Pereira, 1989; Pereira, 1993; Jolly et al., 2000; Ichino, 2006; Ichino and Koyama, 2006). Moreover, as in this case, closely related individuals (here: two subadult females from M2) may take sides in ongoing targeted aggression (Vick and Pereira, 1989; Nakamichi and Koyama, 1997). However, in contrast to previous reports of targeted aggression, the victims belonged to the dominant matriline. Therefore, these events of targeted aggression by the subordinates could be seen as an initiation of a changeover of power in the group, and in fact they resulted in a dominance status reversal (Pereira, 1993).

In ring-tailed lemurs, targeted aggression and group fission both increase with group size (Jolly et al., 1993; Ichino and Koyama, 2006). Most reported cases of fissions or evictions of females usually took place when a group reached a size of about 15-25 individuals and were initiated by incidents of targeted aggression (Sussman, 1991; Jolly et al., 2002; Gould et al., 2003; Ichino, 2006; Ichino and Koyama, 2006). Therefore, it is possible, since group A consisted of 14 individuals plus 4 infants at the time of the events, that the whole incident was a group fission event, initiated by targeted aggression. The initiation of this event was, in accordance with former observations (e.g. Ichino, 2006), the conflict between two different matrilines, of which one was evicted from the group in the end. However, the fact that the targeted and evicted matriline was the originally the highest- 
ranking one contrasts with most observed cases so far (Taylor and Sussman, 1985; Koyama, 1991; Sussman, 1991; Jolly et al., 2002; Koyama et al., 2002; Gould et al., 2003).

Since the reported events happened in captivity, limitations in space use might be one possible explanation for increased aggression in the group. Depending on the habitat quality, the home range sizes of ring-tailed lemurs vary strongly in the wild (Sussman, 1991). In Madagascar's gallery forests they most commonly occupy home ranges from 6 to 30 ha (Sussman, 1991; Sauther et al., 1999; Mertl-Millhollen et al., 2003), while in drier habitats home ranges of up to 87-132 ha have been reported (Kelley, 2013). In richer habitats or during wet season, however, home ranges can also be as small as 2.6 ha (Gabriel, 2013). With high-quality food provisioning twice a day, Affenwald most likely falls within the definition of a rich habitat and smaller home ranges sizes should be expected. Nevertheless, since two groups share an enclosure of 3.5 ha, crowding might have influenced the level of aggression in these events. Under natural settings the two targeted females might have just migrated further away after being evicted from the group and settled elsewhere to start a new group (Koyama, 1991). However, for captivity, 3.5 ha is still a large enclosure, which usually offers enough space for the individuals to avoid each other if necessary.

One possible advantage of female intratroop infanticide of ring-tailed lemurs is the elimination of resource competitors for their own offspring. However, female infanticide could also occur as collateral damage of intense aggressive interactions during females' struggle for dominance (Hrdy, 1979; Hrdy et al., 1995; Sussman et al., 1995; Jolly et al., 2000; Charpentier and Drea, 2013). Another plausible explanation for the infanticide and subsequent lethal aggression might be female reproductive competition (e.g. Hrdy, 1979; Vick and Pereira, 1989; Kappeler, 1993). In particular, since the subadult females of the subordinate matriline (M2) approached maturity, while the dominant females (M1) failed to reproduce successfully for the past 2 years already, most individuals were related to the subordinate matriline (M2). It has been suggested that the likelihood of targeted aggression and evictions increases with the number of adult females and when the group sex ratio is unbalanced (Vick and Pereira, 1989; Kappeler, 1993). Moreover, aggression is especially high during birth season, while the females are lactating (Vick and Pereira, 1989; Pereira, 1993), and mothers with young infants have been observed to be particularly aggressive (Hood and Jolly, 1995). In the context of female reproductive competition, higher-ranking females have been observed to keep lower-ranking mothers away from their own infants, presumably to prevent them from nursing (Gould, 1990). Like in the reported events, other observations of female reproductive competition were more drastic, when females of the same group attacked and killed infants of usually subordinate females or injured them severely (Jolly et al., 2000). Nevertheless, after such extreme events of female competition, including infant killing, the dominance statuses between the females are usually clear or an eviction of one or several females resolves the conflict (Vick and Pereira, 1989; Koyama, 1991; Jolly et al., 2000; Ichino, 2006). The case reported in this study is, to our knowledge, the first female competition in ring-tailed lemurs with such an extreme and lethal level of aggression, with two females being not just evicted but lethally injured.

In conclusion, these events might have been the result of an initiation of a group fission due to the growing group size, as well as an act of female competition, resulting in a total changeover of power between the two main matrilines in the group. However, the exact circumstances of the events leading up to the lethal injuries, including the role of males, remain obscure, highlighting the need for additional studies of the causes, mechanisms and consequences of this rare and explicit form of female competition.

Acknowledgements. We want to thank the entire staff of Erlebnispark Affenwald for sharing their observations and knowledge about the described events with us. Special thanks go to Claudia Fichtel and Peter Kappeler for their help and comments on this article. Finally, we want to thank Michelle Sauther, Richard Lawler and one anonymous reviewer for their thoughtful and constructive comments on an earlier version of this article.

Edited by: U. Radespiel

Reviewed by: M. Sauther, R. Lawler, and one anonymous referee

\section{References}

Andrews, J.: Infanticide by a female black lemur, Eulemur macaco, in disturbed habitat on Nosy Be, North-Western Madagascar, Folia Primatol., 69, 14-17, 1998.

Bartlett, T. Q., Sussman, R. W., and Cheverud, J. M.: Infant killing in primates: A review of observed cases with specific reference to the sexual selection hypothesis, Am. Anthropol., 95, 958-990, 1993.

Budnitz, N. and Dainis, K.: Lemur catta: Ecology and behaviour, in: Lemur Biology, edited by: Tattersall, I. and Sussman, R. W., Plenum, New York, 219-235, 1975.

Charpentier, M. J. E. and Drea, C. M.: Victims of infanticide and conspecific bite wounding in a female-dominant primate: A long-term study, PLOS ONE, 8, e82830, doi:10.1371/journal.pone.0082830, 2013.

Digby, L. J.: Infant care, infanticide, and female reproductive strategies in polygynous groups of common marmosets (Callithrix jacchus), Behav. Ecol. Sociobiol., 37, 51-61, 1995.

Erhart, E. M. and Overdorff, D. J.: Rates of agonism by diurnal lemuroids: Implications for female social realtionships, Int. J. Primatol., 29, 1227-1247, 2008.

Fawcett, K. and Muhumuza, G.: Death of a wild chimpanzee community member: possible outcome of intense sexual competition?, Am. J. Primatol., 51, 243-247, 2000.

Gabriel, D. N.: Habitat use and activity patterns as an indication of fragment quality in a strepsirrhine primate, Int. J. Primatol., 34, 388-406, 2013. 
Goodall, J.: Infant-killing and cannibalism in free-living chimpanzees, Folia Primatol., 28, 259-282, 1977.

Gould, L.: The social development of free-ranging infant Lemur catta at Berenty Reserve, Madagascar, Int. J. Primatol., 11, 297318, 1990.

Gould, L., Sussman, R. W., and Sauther, M. L.: Demographic and life-history patterns in a population of ring-tailed lemurs (Lemur catta) at Beza Mahafaly Reserve, Madagascar: A 15-year perspective, Am. J. Phys. Anthropol., 120, 182-194, 2003.

Gros-Louis, J., Perry, S., and Manson, J. H.: Violent coalitionary attacks and intraspecific killing in wild white-faced capuchin monkeys (Cebus capucinus), Primates, 44, 341-346, 2003.

Hood, L. C.: Infanticide among ringtailed lemurs (Lemur catta) at Berenty Reserve, Madagascar, Am. J. Primatol., 33, 65-69, 1994.

Hood, L. C. and Jolly, A.: Troop fission in female Lemur catta at Berenty Reserve, Madagascar, Int. J. Primatol., 16, 997-1015, 1995.

Hrdy, S. B.: Infanticide as a primate reproductive strategy, Am. Sci., 65, 40-49, 1977.

Hrdy, S. B.: Infanticide among animals: A review, classification, and examination of the implications for the reproductive strategies of females, Ethol. Sociobiol., 1, 13-40, 1979.

Hrdy, S. B., Janson, C., and van Schaik, C.: Infanticide: Let's not throw out the baby with the bathwater, Evol. Anthropol., 3, 151154, 1995.

Ichino, S.: Attacks on a wild infant ring-tailed lemur (Lemur catta) by immigrant males at Berenty, Madagascar: Interpreting infanticide by males, Am. J. Primatol., 67, 267-272, 2005.

Ichino, S.: Troop Fission in Wild Ring-Tailed Lemurs (Lemur catta) at Berenty, Madagascar, Am. J. Primatol., 68, 97-102, 2006.

Ichino, S. and Koyama, N.: Social changes in a wild population of ringtailed lemurs (Lemur catta) at Berenty, Madagascar, in: Ringtailed lemur biology: Lemur catta in Madagascar, edited by: Jolly, A., Sussman, R. W., Koyama, N., and Rasamimanana, H., Springer-Verlag, New York, 234-244, 2006.

Jolly, A. (Ed.): Lemur behavior: A Madagascar field study, Chicago (IL): Univ. Chicago Press, 1966.

Jolly, A.: Pair-bonding, female aggression and the evolution of lemur societies, Folia Primatol., 69, 1-13, 1998.

Jolly, A.: Mammals: Lemur catta, ring-tailed lemur, Maky, in: The natural history of Madagascar, edited by: Goodman, S. M. and Benstead, J. P., Chicago University Press, 1329-1331, 2003.

Jolly, A., Caless, S., Cavigelli, S., Gould, L., Pereira, M. E., Pitts, A., Pride, R. E., Rabenandrasana, H. D., Walker, J. D., and Zafison, T.: Infant killing, wounding and predation in Eulemur and Lemur, Int. J. Primatol., 21, 21-40, 2000.

Jolly, A., Rasamimanana, H. R., Kinnaird, M. F., O’Brien, T. G., Crowley, H. M., Harcourt, C. S., Gardner, S., and Davidson, J.: Territoriality in Lemur catta groups during the birth season at Berenty, Madagascar, in: Lemur social systems and their ecological basis, edited by: Kappeler, P. M. and Ganzhorn, J. U., Plenum Press, New York, 85-109, 1993.

Jolly, A., Dobson, A., Rasamimanana, H. M., Walker, J., O’Connor, S., Solberg, M., and Perel, V.: Demography of Lemur catta at Berenty Reserve, Madagascar: effects of troop size, habitat and rainfall, Int. J. Primatol., 23, 327-353, 2002.

Kappeler, P. M.: Female dominance in Lemur catta: More than just female feeding priority?, Folia Primatol., 55, 92-95, 1990.
Kappeler, P. M.: Variation in social structure: The effects of sex and kinship on social interactions in three lemur species, Ethology, 93, 125-145, 1993.

Kappeler, P. M. and Fichtel, C.: Female reproductive competition in Eulemur rufifrons: eviction and reproductive restraint in a plurally breeding Malagasy primate, Mol. Ecol., 21, 685-698, 2012.

Kelley, E. A.: The ranging behavior of Lemur catta in the region of Cap Sainte-Marie, Madagascar, Am. J. Phys. Anthropol., 150, 122-132, 2013.

Koyama, N.: Troop division and intertroop relation of ring-tailed lemurs (Lemur catta) at Berenty, Madagascar, in: Primatology today, edited by: Ehara, A., Kimura, T., Takenaka, O., and Iwamoto, M., Elsevier Science Publishers, 173-176, 1991.

Koyama, N., Nakamichi, M., Ichino, S., and Takahata, Y.: Population and social dynamics changes in ring-tailed lemur troop at Berenty, Madagascar between 1989-1999, Primates, 43, 291314, 2002.

Marzec, A. M., Kunz, J. A., Falkner, S., Atmoko, S. S. U., Alavi, S. E., Moldawer, A. M., Vogel, E. R., Schuppli, C., van Schaik, C. P., and van Noordwijk, M. A.: The dark side of the red ape: male-mediated lethal female competition in Bornean orangutans, Behav. Ecol. Sociobiol., 70, 459-466, 2016.

Mertl-Millhollen, A. S., Moret, E. S., Felantsoa, D., Rasamimanana, H., Blumenfeld-Jones, K. C., and Jolly, A.: Ring-tailed lemur home ranges correlate with food abundance and nutritional content at a time of environmental stress, Int. J. Primatol., 24, 969985, 2003.

Mittermeier, R. A., Konstant, W. R., Hawkins, F., Louis, E. E., Langrand, O., Ratsimbazafy, J., Rasoloarison, R., Ganzhorn, J. U., Rajaobelina, S., Tattersall, I., and Meyers, D. M. (Eds.): Lemurs of Madagascar, 2nd Edn., Conservation International, 2006.

Muroyama, Y. and Thierry, B.: Fatal attack on an infant by an adult female tonkean macaque, Int. J. Primatol., 17, 219-227, 1996.

Nakamichi, M. and Koyama, N.: Social relationships among ringtailed lemurs (Lemur catta) in two free-ranging troops at Berenty Reserve, Madagascar, Int. J. Primatol., 18, 73-93, 1997.

Pereira, M. E.: Agonistic interactions, dominance relation, and ontogenetic trajectories in ringtailed lemurs, in: Juvenile Primates: Life history, development, and behavior, edited by: Pereira, M. E. and Fairbanks, L. A., Oxford University Press, New York, 285305, 1993.

Pereira, M. E. and Kappeler, P. M.: Divergent systems of agonistic behaviour in lemurid primates, Behaviour, 134, 225-274, 1997.

Sauther, M. L.: Reproductive behavior of free-ranging Lemur catta at Beza Mahafaly Special Reserve, Madagascar, Am. J. Phys. Anthropol., 84, 463-477, 1991.

Sauther, M. L., Sussman, R. W., and Gould, L.: The socioecology of the ringtailed lemur: Thirty-five years of research, Evol. Anthropol., 8, 120-132, 1999.

Sussmann, R. W.: Demography and social organization of freeranging Lemur catta in the Beza Mahafaly Reserve, Madagascar, Am. J. Phys. Anthropol., 84, 43-58, 1991.

Sussman, R. W., Cheverud, J. M., and Bartlett, T. Q.: Infant killing as an evolutionary strategy: Reality or myth?, Evol. Anthropol., 3, 149-151, 1995.

Taylor, L. and Sussman, R. W.: A preliminary study of kinship and social organization in a semi free-ranging group of Lemur catta, Int. J. Primatol., 6, 601-614, 1985. 
Valero, A., Schaffner, C. M., Vick, L. G., Aureli, F., and RamosFernandez, G.: Intragroup lethal aggression in wild spider monkeys, Am. J. Primatol., 68, 732-737, 2006.

van Schaik, C. P.: Infanticide by male primates: the sexual selection hypothesis revisited, in: Infanticide by males and its implications, edited by: van Schaik, C. P. and Janson, C. H., Cambridge University Press, Cambridge, 27-61, 2000.
Vick, L. G. and Pereira, M. E.: Episodic targeting aggression and the histories of Lemur social groups, Behav. Ecol. Sociobiol., 25, 3-12, 1989.

Watts, D. P.: Intracommunity coalitionary killing of an adult male chimpanzee at Ngogo, Kibale National Park, Uganda, Int. J. Primatol., 25, 507-521, 2004. 